\title{
0 princípio da autonomia na universidade brasileira: sentidos em disputa
}

\author{
The autonomy principle in the brazilian university: \\ meanings in dispute \\ El principio de la autonomía en la universidad brasileña: \\ significados en disputa \\ JOVILES VITÓRIO TREVISOL \\ http://orcid.org/0000-0001-9873-2688 \\ Universidade Federal da Fronteira Sul \\ Faculdade de Sociologia \\ Centro de Estudos Sociais \\ Coimbra, Portugal \\ RICARDO GARMUS \\ http://orcid.org/0000-0002-2572-6890 \\ Universidade Federal da Fronteira Sul \\ Faculdade de Ciências Sociais \\ Departamento de Estudos Sociais \\ Santa Catarina, SC, Brasil
}

Resumo: O princípio da autonomia tem estado no centro das discussões desde a criação das primeiras universidades. Os tensionamentos têm sido motivados, em geral, pelas disputas presentes no interior da sociedade e do Estado. $\mathrm{O}$ objetivo deste texto é apresentar os resultados de um estudo sobre a autonomia na tradição universitária brasileira. A pesquisa evidenciou, entre outros aspectos, uma estreita correlação entre democracia e autonomia.

Palavras-chave: Política educacional. Educação superior. Autonomia universitária. Constituição de 1988.

Abstract: The autonomy principle has been at the center of discussion since the creation of the first universities. The tensions have been, in general, motivated by political disputes presented in the interior of the society and the State. The purpose of this article is to present the results of a study regarding autonomy in the Brazilian university tradition. The research showed, among other aspects, the strict correlation between democracy and autonomy.

Keywords: Educational policies. Higher education. University Autonomy. Constitution of 1988. 
Resumen: El principio de la autonomía ha estado en el centro de las discusiones desde la creación de las primeras universidades. Las tensiones sido, en general, motivadas por disputas políticas presentadas en el interior de la sociedad y del Estado. El propósito de este artículo es presentar los resultados de un estudio sobre la autonomía en la tradición universitaria brasileña. La investigación evidenció, entre otros aspectos, una correlación estrecha entre democracia y autonomía.

Palabras-clave: Politicas educacionales. Educación superior. Autonomía universitaria. Constitución de 1988.

\section{INTRODUÇÃO}

O princípio da autonomia tem estado no centro das discussões desde a criação das primeiras universidades na Europa. Ele pode ser traduzido como autogoverno ou como o direito de definir as próprias normas acadêmicas, administrativas e de gestão (MEYER, 2019). Ele está alicerçado na noção de território livre e de imunidade em relação às pressões externas. Trata-se, como observa Rossato (1998), de um princípio medieval herdado da Igreja Católica que, ao longo dos séculos, tem protegido as universidades das interferências externas. A título de ilustração, na baixa Idade Média (contexto do surgimento das primeiras universidades europeias como Bolonha, Paris, Cambridge, Oxford, Coimbra, etc.), foram frequentes os conflitos entre a população local e a comunidade estudantil. A população resistia em aceitar a proteção que as autoridades eclesiásticas conferiam aos mestres e aos estudantes. Era comum o papado manifestar-se em defesa da comunidade universitária, concedendo direitos especiais aos estudantes e aos mestres, livrando-os, inclusive, de acusações de delitos (ROSSATO, 1998). As autoridades locais não tinham poder de intervenção sobre os espaços onde ocorriam as aulas e sobre o cotidiano das instituições.

A despeito das tensões, pode-se afirmar que o princípio da autonomia foi basilar para a sobrevivência e a consolidação desse modelo específico de instituição, cujo propósito tem sido, ao longo dos séculos, promover a formação de nível superior e o desenvolvimento da investigação científica e do pensamento crítico. Como destaca Chaui (2003, p. 4-5), trata-se de um princípio que assegurou às universidades as condições para se diferenciarem das demais instituições:

[...] A legitimidade da universidade moderna fundou-se na conquista da ideia de autonomia do saber em face da religião e do Estado, portanto, na ideia de um conhecimento guiado por sua própria lógica, por necessidades imanentes a ele, tanto do ponto de vista de sua invenção ou descoberta como de sua transmissão. Em outras palavras, sobretudo depois da Revolução Francesa, a universidade concebe-se a si mesma como uma instituição republicana e, portanto, pública e laica. 
Ao longo dos seus quase mil anos de existência foram incontáveis os ataques, as intervenções, as perseguições e as invasões às instituições universitárias, promovidos por agentes públicos e privados que visavam ao cerceamento das liberdades e do pensamento crítico. Entre os mais conhecidos e ilustrativos atos de intervenção está o que ocorreu na Universidade de Salamanca durante a Guerra Civil Espanhola, envolvendo o então reitor Miguel de Unamuno e o general franquista Millán Astray. Os incidentes culminaram na deposição do reitor em 1936.

É difícil supor qual teria sido o destino das instituições universitárias sem a salvaguarda proveniente desse princípio. Os conflitos no campo da autonomia foram, em geral, motivados pelas disputas políticas presentes no interior da sociedade e do Estado. A história da educação superior no Brasil, inclusive nos anos recentes, oferece evidências sobre as permanentes tensões entre educação e política, ciência e ideologia, universidade e sociedade etc. As disputas e os conflitos variam de acordo com o contexto de cada época e com as orientações político-ideológicas dos grupos hegemônicos que controlam o Estado. Os regimes autoritários, em geral, têm sido ávidos na tentativa de substituir as agendas de Estado pelas de governo, impondo determinados alinhamentos ideológicos e controles às universidades.

Tendo em vista a problemática acima, o propósito deste artigo é analisar a autonomia na história da universidade brasileira. Entendemos que esse exercício de hermenêutica é importante para compreender as raízes políticas e ideológicas das disputas. Trata-se, do ponto de vista metodológico, de um estudo de natureza documental desenvolvido entre agosto de 2019 e fevereiro de 2021. Além da extensa pesquisa bibliográfica, a investigação envolveu a organização e a análise de um amplo conjunto de documentos que estabeleceram os marcos regulatórios da educação superior em cada época, cabendo destaque para as diferentes Constituições, Leis de Diretrizes e Bases da Educação Nacional, leis, decretos, portarias, acórdãos etc. Tendo em vista as diferentes naturezas jurídicas das instituições de educação superior no Brasil, o presente estudo priorizou o segmento das universidades públicas.

\section{AS ORIGENS DA EDUCAÇÃO SUPERIOR BRASILEIRA}

A universidade brasileira é tardia. Por razões políticas bastante conhecidas, a Coroa portuguesa freou toda e qualquer iniciativa destinada a oferecer educação superior na Colônia. As políticas adotadas foram de tal modo restritivas que o primeiro curso de nível superior (o Colégio Médico-Cirúrgico da Bahia) passou a existir apenas em março de 1808, decorrente de um decreto de D. João VI, assinado 
poucos dias após a sua chegada ao Brasil. Similar ao que havia feito ao aportar na Bahia, criou, no mesmo ano, o segundo curso superior de medicina na cidade do Rio de Janeiro. Entre 1808 e 1821, período de sua permanência no Brasil, D. João VI instituiu sete cursos superiores, hoje pertencentes às universidades Federais do Rio de Janeiro e da Bahia (TEIXEIRA, 1989; DURHAM, 1989).

No período colonial (1500-1822) a ausência de cursos de nível superior em universidades foi compensada por meio dos ciclos de estudos superiores em filosofia e em teologia destinados aos estudantes seminaristas que ambicionavam o sacerdócio. Após a expulsão dos Jesuítas em 1759 foram criadas aulas de matérias isoladas e alguns poucos cursos no Rio de Janeiro e no Recife (ROSSATO, 1998). Como destacado acima, a chegada da Família Real fortaleceu os debates sobre a criação da primeira universidade no Brasil. De acordo com Martins (2002), apenas no período entre 1808 e 1822 foram apresentados 24 projetos de universidades, sendo nenhum deles aprovado. A independência política de 1822 não trouxe mudanças significativas no campo da educação superior. A despeito de ter sido objeto de longos e acalorados debates durante o processo de elaboração da Constituinte de 1824, os avanços foram mínimos. Cabe destacar que a Assembleia Constituinte foi dissolvida por D. Pedro I em 12 de novembro de 1823. Como descreve Barreto (2007, p. 1.785):

Inúmeras variantes foram apresentadas, estipulando a fundação de uma, duas ou três universidades em diferentes pontos do país. Alguns dos argumentos defendidos eram de um bairrismo gritante, em que deputados se contrapunham a outros enaltecendo as vantagens de sua província contra os vícios de outras. Um aparte interessante se deveu ao deputado cearense José Martiniano de Alencar: 'Belos discursos tenho ouvido dos ilustres deputados que têm falado, pretendendo cada um que se deve estabelecer a universidade na província que lhe parece. Precisamos, Sr. Presidente, de uma universidade e já, como de pão para a boca'. Tudo isto acabou melancolicamente com o decreto de dissolução da Constituinte pelo Imperador em 12 de novembro de 1823.

Em 1842, o então deputado José Cesário de Miranda Ribeiro (Visconde de Uberaba) apresentou ao Legislativo do Império um projeto que previa a criação da universidade Pedro II, na cidade do Rio de Janeiro. O projeto, em seu artigo $2^{\circ}$, previa que a universidade reuniria:

[...] as faculdades de teologia, matemáticas, filosofia e medicina: e assim mais um curso de ciências físico-matemática, o qual será de sete anos para os militares engenheiros, de cinco para os artilheiros, de três para os militares que se aplicarem à arma de cavalaria, ou à infantaria, e à marinha; um curso farmacêutico, outro de parto; e a faculdade de letras, que prepare os alunos para os estudos universitários (BARRETO, 2007, p. 1.785). 
O projeto do Visconde de Uberaba não prosperou. No ano seguinte, em 1843, o então senador Manoel do Nascimento Castro e Silva retomou a proposta. Em 1847 um projeto similar foi apresentado pelo Visconde de Goiana. Em 1870 o então ministro do Império, Paulino José Soares de Souza (Visconde do Uruguai), submeteu novo projeto aos deputados, demonstrando estar preocupado com os rumos da educação superior no Brasil. Em 1871, a proposta de criação de universidade foi reapresentada. Segundo Barreto (2007), após anos de discussão o então ministro do Império, Barão Homem de Melo, resolveu dar sequência ao processo de estruturação da primeira universidade no Brasil. De acordo com o projeto, a instituição se chamaria "Universidade Pedro II" e funcionaria como uma espécie de guarda-chuva abrigando todas as faculdades brasileiras existentes. Homem de Melo, em sua exposição de motivos, assim se referiu:

Parece-me fora de dúvida que o centro universitário deve ser a capital do Império; e digo propositalmente - centro universitário - para indicar que não cabe em meu espírito ideia de suprimir ou extinguir qualquer das faculdades que existem nas províncias, senão a de subordiná-las, como partes integrantes do mesmo todo, à universidade que entendo aí se deve estabelecer (BARRETO, 2007, p. 1.786).

O projeto novamente não logrou êxito. A proposta de subordinar as faculdades provinciais a uma única instituição sediada no Rio de Janeiro atraiu a crítica das Províncias, pois, segundo eles, a centralização retiraria poder de controle e influência em âmbito regional. Além disso, algumas lideranças positivistas da época, entre as quais Miguel Lemos, se colocaram contra o projeto sob o argumento de que:

[...] o Brasil possui um número mais que suficiente de escolas superiores para satisfazer às necessidades profissionais, e que a fundação de uma universidade só teria como resultado estender e dar maior intensidade às deploráveis pretensões pedantocráticas da nossa burguesia, cujos filhos abandonam as demais profissões, igualmente úteis e honrosas, para só preocupar-se com a aquisição de um diploma qualquer (LEMOS, 1881, Apud. BARRETO, 2007, p. 1.786).

As resistências inviabilizaram o projeto. A Monarquia foi extinta no Brasil em 1889 sem ter dado ao país uma universidade. Durante todo o século XIX a educação superior ficou restrita a institutos isolados, com características marcadamente profissionalizantes e tutelados pelo Estado (FREITAG, 1980). Ao invés de universidades, foram criadas escolas superiores nas principais cidades da época (TEIXEIRA, 1989; MARTINS, 2002). Até o fim da primeira República a elite brasileira não assumiu a defesa da universidade. Ela continuou defendendo a tese de que a formação de nível superior deveria ser buscada no exterior. A 
criação, em 1890, do Ministério da Instrução Pública, Correios e Telégrafos criou alguma expectativa, mas a opção foi continuar autorizando a abertura das escolas superiores. De acordo com Rossato (1998), no período entre 1891 e 1910 foram criadas 27 escolas superiores.

A implantação da República, neste sentido, não alterou substancialmente as políticas educacionais do Império. A primeira Constituição republicana, a propósito, foi totalmente omissa em relação aos compromissos do Estado em relação à educação superior. Após uma série de tentativas frustradas, em 7 de setembro de 1920 o então presidente Epitácio Pessoa criou a Universidade do Rio de Janeiro (atual UFRJ). Sete anos depois, em 7 de setembro de 1927, o então presidente do estado de Minas Gerais, Antônio Carlos de Andrada, criou a Universidade de Minas Gerais (atual UFMG). A universidade brasileira é, neste sentido, obra do século XX.

\section{OS PRIMEIROS MARCOS REGULATÓRIOS}

Até a década de 30 do século passado as discussões sobre a autonomia universitária foram inexistentes devido ao próprio modelo de organização (centrífugo), formado por faculdades isoladas sediadas nas Províncias e fortemente tuteladas pelo Estado. O tema da autonomia entrou na agenda do país a partir da criação das primeiras universidades. O surgimento desse novo e específico modelo de instituição fez emergir o debate sobre os limites da intervenção político-partidária, estatal e religiosa no ambiente universitário.

De acordo com a pesquisa realizada, os primeiros atos disciplinando a autonomia universitária foram expedidos no início do governo Vargas. No dia 30 de dezembro de 1930, menos de dois meses no exercício do cargo, Vargas expediu o Decreto $\mathrm{n}^{\circ}$ 19.547, estabelecendo que fica "[...] cassada a autonomia didática à Universidade de Minas Gerais” (Art. 1º, BRASIL, 1930). A intervenção foi justificada sob o argumento de que o governo estava preparando uma ampla reforma educacional.

A referida reforma, coordenada por Francisco Campos, materializou-se em seguida por meio de seis Decretos, promulgados a partir de abril de 1931. De acordo com Romanelli (1978), os decretos emitidos pelo então Ministro da Educação e Saúde Pública tinham o objetivo de organizar, estruturar e centralizar na administração federal os cursos superiores, o ensino secundário e o ensino comercial (ensino médio profissionalizante). Como é possível observar abaixo, no excerto do Decreto 19.850, de 11 de abril de 1931, Francisco Campos entendia que o país não estava preparado para conferir autonomia integral às universidades (BRASIL, 1931): 
[...] Seria, porém, de todo ponto inconveniente e mesmo contraproducente para o ensino, que, de súbito, por uma integral e repentina ruptura com o presente, se concedesse às Universidades ampla e plena autonomia didactica e administrativa. Autonomia requer prática, experiência e critérios seguros de orientação. Ora, o regimen universitario ainda se encontra entre nós na sua phase nascente, tendo os primeiros passos e fazendo os seus ensaios de adaptação. Seria de mau conselho que, nesse período inicial e ainda embryonario e rudimentar da organização universitaria, se tentasse, com risco de graves damnos para o ensino, o regimen da autonomia integral [...] (Sic. Preservada a redação original).

A Reforma Educacional de 1931 refletiu as teses do governo Vargas. A educação foi concebida como parte das políticas de segurança nacional. De acordo com Campos, o Estado "[...] precisa exercer de modo efetivo o controle de todas as atividades sociais, a economia, a política, a educação" (CIRNE, 2018, p. 48). O Decreto no $19.851 / 31$ é um dos seis Decretos da Reforma Educacional promovida por Campos em 1931. Em relação à autonomia universitária, o Artigo $9^{\circ}$ assim se refere: (BRASIL, 1931):

Art. $9^{\circ}$ As universidades gosarão de personalidade juridica e de autonomia administrativa, didactica e disciplinar, nos limites estabelecidos pelo presente decreto, sem prejuizo da personalidade juridica que tenha ou possa ser atribuida pelos estatutos universitarios a cada um dos institutos componentes da universidade.

Paragrapho unico. Nas universidades officiaes, federaes ou estaduaes, quaesquer modificações que interessem fundamentalmente á organizacção administrativa ou didactica dos institutos universitarios, só poderão ser effectivadas mediante sancção dos respectivos governos, ouvido o Conselho Nacional de Educação (Sic. Preservada a redação original).

A vertente autoritária do primeiro governo Vargas materializou-se de várias maneiras na área educacional. No contexto da implantação do Estado Novo em 1937, o então Ministro da Educação Gustavo Capanema Filho elaborou um projeto de lei, em seguida sancionado por Getúlio Vargas (Lei no 452/37), estabelecendo a extinção da Universidade do Rio de Janeiro (criada em 1920) e instituindo a Universidade do Brasil. A Lei $n^{\circ}$ 452/37 alterou o nome da instituição, extinguiu departamentos e criou institutos. A Lei, a propósito, não faz qualquer menção à autonomia universitária.

O fim do Estado Novo também não representou significativa alteração dos marcos regulatórios. A Constituição de 1946, a propósito, não faz menção à autonomia universitária. $\mathrm{O}$ assunto foi retomado no bojo do processo de elaboração da LDB de 1961. O Art. 80 da nova LDB (Lei no 4.024, de 20 de 
dezembro de 1961) assim se refere: "As Universidades gozarão de autonomia didática, administrativa, financeira e disciplinar, que será exercida na forma de seus estatutos" (BRASIL, 1961).

\section{A AUTONOMIA UNIVERSITÁRIA NO CONTEXTO DA DITADURA CIVIL-MILITAR}

A educação superior, assim como todas as demais dimensões da vida social e política brasileira, foi afetada pelo golpe de 31 de março de 1964. O autoritarismo e a repressão passaram a ser práticas institucionalizadas nas universidades. Além do permanente controle e repressão (GERMANO, 2000), o regime não tardou a alterar os marcos regulatórios da educação superior. Em 02 de julho de 1968, no período mais intenso da ditadura, foi publicado o Decreto ${ }^{\circ}$ 62.937/68 criando o Grupo de trabalho (GTRU) responsável pela elaboração de uma análise da educação superior brasileira. O Relatório elaborado pelo GTRU recomendou, entre outros aspectos, "[...] uma ação eficaz que enfrentasse de imediato o problema da reforma universitária, convertida numa das urgências nacionais" (FÁVERO, 2006, p. 36). Dada a urgência, em pouco mais de trinta dias o GTRU finalizou o projeto de reforma universitária. O propósito era, como descreve Germano (2000, p. 133), "estancar urgentemente a crise política”. O projeto foi elaborado pelo GTRU, aprovado pelo Congresso e sancionado pelo então presidente Costa e Silva (Lei no 5.540/68) entre julho e novembro de 1968, tendo sido sancionado quinze dias antes do Ato Institucional $\mathrm{n}^{\circ} 5$.

Em relação à autonomia universitária o Art. $3^{\circ}$ da Lei 5.540/68 assim se refere: "As universidades gozarão de autonomia didático-científica, disciplinar, administrativa e financeira, que será exercida na forma da lei e dos seus estatutos" (BRASIL, 1968). Curiosamente os demais parágrafos e incisos foram vetados. Além da sua natureza autoritária, a Reforma Universitária (RU) de 1968 foi concebida no bojo de um conjunto de acordos MEC/USAID, celebrados a partir de 1964. Alguns assessores norte-americanos, entre os quais Rudolph Atcon, participaram da elaboração da RU. O Relatório Acton, de 1966, enfatizou a necessidade de disciplinar a vida acadêmica, coibir protestos, reforçar a hierarquia e racionalizar a universidade, organizando-se em moldes empresariais (GERMANO, 2000). 
No dia 13 de dezembro de 1968, duas semanas após a publicação da $\mathrm{RU}$, foi promulgado o Ato Institucional $\mathrm{n}^{\circ} 5$, considerado o mais duro ato de cerceamento dos direitos fundamentais e das liberdades individuais e coletivas. O AI-5 teve consequências imediatas sobre as universidades e o movimento estudantil, tendo resultado na perseguição de estudantes e professores, na aposentadoria compulsória de docentes, na expulsão de estudantes e na demissão de servidores.

Cerca de dois meses após o AI-5, em 26 de fevereiro de 1969, foi publicado o Decreto 477/69, definindo as infrações disciplinares a serem aplicadas a professores, alunos, funcionários ou empregados de estabelecimentos de ensino público ou particulares. O referido Decreto estabeleceu rito sumário para demissões e desligamentos das pessoas consideradas subversivas. No rol das infrações disciplinares estava a participação de atos de paralisação das atividades escolares, a organização de eventos não autorizados, a confecção ou porte de material subversivo, as manifestações que comprometessem a ordem pública, o sequestro de pessoas e a prática de atentados contra o patrimônio das universidades (CARRANO, 2018). Em seus dez anos de vigência, o Decreto imprimiu marcas profundas na cultura institucional das universidades e na formação política dos estudantes.

\section{A AUTONOMIA UNIVERSITÁRIA NA CF DE 1988}

Os debates sobre a autonomia universitária foram retomados nos anos 80, especialmente durante o período constituinte. A Constituição Federal (CF) de 1988 foi o primeiro texto constitucional brasileiro a estabelecer a autonomia como um princípio fundamental do fazer universitário, tanto nos seus aspectos didático-científicos, quanto administrativos, de gestão financeira e patrimonial. No inciso II, do Art. 206, a CF estabelece que a "liberdade de aprender, ensinar, pesquisar e divulgar o pensamento, a arte e o saber" é um dos princípios do ensino.

A Assembleia Nacional Constituinte recebeu inúmeras emendas, entre as quais do então deputado Nelson Wedekin (Emenda 8S0463-6), propondo o acréscimo de um dispositivo assegurando que a administração das universidades será formada por professores, alunos e funcionários. Após longos debates e votações, o Art. 207, em sintonia com todo o Capítulo III da CF, ficou com a seguinte redação: 
Art. 207. As universidades gozam de autonomia didático-científica, administrativa e de gestão financeira e patrimonial, e obedecerão ao princípio de indissociabilidade entre ensino, pesquisa e extensão.

$\int 1^{\circ}$ É facultado às universidades admitir professores, técnicos e cientistas estrangeiros, na forma da lei.

$2^{\circ} \mathrm{O}$ disposto neste artigo aplica-se às instituições de pesquisa científica e tecnológica (BRASIL, 1988).

De acordo com Ranieri (2018), a CF assegurou as bases para o autogoverno e para o exercício das liberdades essenciais ao trabalho acadêmico e à gestão democrática. Após décadas de embates, o Art. 207 finalmente reconheceu a centralidade do princípio, assegurando ao sistema universitário as garantias constitucionais para o pleno exercício do direito ao autogoverno. As universidades públicas, em particular, passaram a gozar da condição de instituições de Estado, ficando protegidas do varejo das disputas político-partidárias e dos interesses patrimonialistas dos grupos que ocupam as estruturas do Estado.

Em consonância com CF, a Lei de Diretrizes e Bases da Educação Nacional (Lei 9.394/96) reforçou os compromissos com o princípio da autonomia. Os artigos 53 e 54 da LDBEN garantem às universidades o direito de decidir sobre os cursos, programas, currículos, pesquisas, investimentos, organização interna, regramentos etc. Como observam Ranieri e Lutaif (2019), as universidades públicas, em particular, passaram a gozar de uma posição singular no corpo da Administração Indireta, caracterizada pela possibilidade de gozarem de estatuto jurídico especial para atender às peculiaridades de sua estrutura, organização e financiamento. Constitucionalmente circunscrita, a autonomia deve ser exercida em observância à legislação nacional vigente, especialmente à relativa ao direito administrativo e educacional.

\section{O PRINCÍPIO DA AUTONOMIA NAS DÉCADAS RECENTES}

A salvaguarda constitucional, a despeito de sua inegável importância, não pôs fim às disputas. Nos anos recentes os questionamentos e os ataques têm sido recorrentes, em geral motivados por agentes públicos, grupos e partidos políticos que questionam a gestão democrática das universidades, a liberdade de cátedra e o direito ao livre exercício do pensamento e da investigação científica. Os embates políticos presentes na sociedade e na estrutura do Estado tencionam a dimensão normativa do preceito constitucional.

De acordo com a pesquisa realizada, a primeira tentativa de alteração do Art. 207 ocorreu três anos após a promulgação da CF. Em 1991, o então presidente Fernando Collor de Mello, apoiado por grupos empresariais da educação privada, apresentou ao Congresso Nacional a Proposta de Emenda Constitucional (PEC) 
$\mathrm{n}^{\mathrm{o}}$ 56-B/1991, cujo propósito era, segundo Leher (2019), desregulamentar a autonomia universitária e mudar o caráter jurídico das universidades federais. A PEC não avançou em virtude da greve nacional dos docentes e técnicoadministrativos em 1991 e o sequente processo de impeachment em 1992.

Os presidentes seguintes, nomeadamente Itamar Franco, Fernando Henrique Cardoso, Luís Inácio Lula da Silva e Dilma Rousseff, não empreenderam tentativas de alteração do Art. 207 da CF. A despeito de terem implementado políticas distintas de expansão e financiamento da educação superior, os governos acima referidos mantiveram seus compromissos e zelaram pelo princípio.

A crise política de 2016 introduziu significativas mudanças no país, inclusive no posicionamento dos governos e de setores da sociedade em relação ao princípio da autonomia. O impeachment da presidente Dilma Rousseff trouxe consigo o esfacelamento das alianças políticas que garantiram apoio às políticas de expansão e de financiamento da educação superior pública e privada no país, por meio do FIES, Reuni, Prouni e tantos outros programas. As universidades públicas, em especial, passaram a ser objetos de recorrentes críticas no parlamento, na imprensa, nas mídias sociais, assim como alvos de denúncia e investigação pelos órgãos de controle e no âmbito da justiça.

O princípio da autonomia passou a ser questionado sob o argumento de que ele era um artifício estrategicamente utilizado para esconder a corrupção e as práticas de desvio de recursos públicos. Como destaca Leher (2019), algumas dessas campanhas foram claramente difamatórias, destinadas a convencer a opinião pública de que as universidades eram ineficientes, corruptas, ociosas e elitizadas. Além do princípio da autonomia, tais campanhas visavam questionar a gratuidade, a gestão democrática e o caráter laico e republicano da universidade pública.

As críticas não tardaram a se transformar em ações na justiça e em processo de investigação criminal. O quadro abaixo, a título de ilustração, apresenta as principais operações coordenadas pela Polícia Federal entre 2016 e 2018, destinadas a investigar denúncias de más condutas nas universidades públicas. 


\section{Quadro 1 - Principais operações da Polícia Federal nas universidades públicas federais (2016-2018)}

\begin{tabular}{|c|c|c|}
\hline OPERAÇÃo & DATA & INSTITUIÇÃO \\
\hline Operação PhD & 09 de dezembro de 2016 & UFRGS \\
\hline Operação Research & 31 de março de 2017 & UFPR \\
\hline Operação Ouvidos Moucos & 14 de setembro de 2017 \\
\hline Operação Esperança Equilibrista & 06 de dezembro de 2017 & UFMG \\
\hline Operação Torre de Marfim & 07 de dezembro de 2017 & UFSC \\
\hline $\begin{array}{c}\text { Operação autorizada pela Justiça Eleitoral } \\
\text { proibindo manifestações político-partidárias }\end{array}$ & 26 de outubro de 2018 & 17 universidades públicas \\
\hline
\end{tabular}

FONTE: Tabela elaborada pelos autores a partir dos dados disponíveis nos sítios do Ministério da Justiça e Segurança Pública e da Polícia Federal.

Nas operações acima chama a atenção a forte exposição midiática e o caráter coercitivo. $\mathrm{Na}$ operação Ouvidos Moucos que prendeu o reitor da Universidade Federal de Santa Catarina participaram 115 policiais. Cerca de três meses depois, em dezembro de 2017, a operação Equilibrista na UFMG envolveu 84 policiais fortemente armados (LEHER, 2019). O caráter repressivo e midiático ficou evidente na operação que prendeu Luis Cancellier de Olivo (ex-reitor da UFSC). Sem crime comprovado, o acusado foi preso em sua residência, conduzido a uma cela de segurança máxima, algemado e submetido à revista íntima. Semanas após, em 02 de outubro de 2017, o então reitor suicidou-se num shopping da cidade de Florianópolis.

No ano seguinte, um novo episódio expôs claramente o incômodo que o princípio da autonomia gera em determinados setores da sociedade. Durante a campanha presidencial de 2018 diversas ações foram impetradas na Justiça Eleitoral requerendo a proibição de assembleias de natureza política e aulas que tratassem de temas políticos, assim como a busca e a apreensão de panfletos e materiais de campanha nas universidades. Tendo em vista o expressivo número de juízes eleitorais que acolheram os pedidos em diversas cidades do país (Belo Horizonte, Campina Grande, Dourados, Niterói, etc.), a então Procuradora-Geral da República, Raquel Dodge, submeteu ao Supremo Tribunal Federal (STF) a propositura de Arguição de Descumprimento de Preceito Fundamental (ADPF) 548.

A ADPF 548 foi relatada pela Ministra Cármen Lúcia Antunes Borges. No dia 31 de outubro de 2018, em sessão plenária, o STF referendou, por unanimidade, a liminar concedida pela Ministra. $O$ parecer passou a ser um marco da jurisprudência sobre a matéria. Segundo o parecer emitido, a autonomia universitária está entre os princípios constitucionais que garantem todas as formas de liberdade: 
[...] A autonomia é o espaço de discricionariedade deixado constitucionalmente à atuação normativa infralegal de cada universidade para o excelente desempenho de suas funções constitucionais. Reitere-se: universidades são espaços de liberdade e de libertação pessoal e política [...] toda forma de autoritarismo é iníqua. Pior quando parte do Estado. Por isso os atos que não se compatibilizem com os princípios democráticos e não garantam, antes restrinjam o direito de livremente expressar pensamentos e divulgar ideias são insubsistentes juridicamente por conterem vício de inconstitucionalidade (ADPF/STF, 2018, p. 13 e 14).

Segundo a liminar, a autonomia é um princípio basilar do Estado Democrático de Direito. Nos termos da liminar “[...] A única força legitimada a invadir a universidade é a das ideias livres e plurais [...] qualquer outra que ali ingresse sem causa jurídica válida é tirana, e tirania é o exato contrário da democracia" (ADPF/STF, 2018, p. 13 e 14); MEYER, 2019, p. 284).

A campanha presidencial de 2018 evidenciou, entre outros tantos aspectos, as diferentes posições dos candidatos sobre a universidade, os seus papéis e as suas formas de organização. A vitória de Jair Messias Bolsonaro levou ao poder um grupo político conservador e resistente ao cumprimento das normas que regem o Estado Democrático de Direito. Em virtude disso, a partir do início do governo Bolsonaro, muitos dos principais questionamentos e ataques à autonomia universitária passaram a ser desencadeados por agentes públicos que exercem importantes funções na estrutura do Estado.

O depoimento abaixo, entre outras tantas manifestações analisadas na presente pesquisa, é bastante ilustrativo. Ele foi expresso pelo então ministro da Educação, Abraham Weintraub, em entrevista ao Jornal da Cidade, em 22 de novembro de 2019:

Foi criada uma falácia que as universidades federais precisam ter autonomia. Justo, autonomia de pesquisa, autonomia de ensino. Só que essa autonomia acabou se transfigurando em soberania. Então, o que você tem? Você tem plantações de maconha, mas não é três pés de maconha, você tem plantações extensivas nas universidades. A ponto de ter borrifador de agrotóxico, porque orgânico é bom contra a soja, para não ter agroindústria no Brasil, na maconha deles, eles querem tudo o que a tecnologia tem à disposição. Ou coisas piores, você pega laboratórios de química, uma faculdade de química não era um centro de doutrinação, desenvolvendo laboratório de droga sintética de metanfetamina (POZZEBOM, 2019).

O governo Bolsonaro tem utilizado a prerrogativa da discricionariedade assegurada pelo Inciso I do Art. 16 da Lei 5.540/68 (BRASIL, 1968) para nomear reitores de acordo com as suas preferências, independentemente da posição na lista tríplice elaborada pelas instituições. $O$ ato de designar o primeiro colocado da lista tríplice para a escolha dos reitores faz parte da tradição universitária, pois 
a lista expressa a vontade da comunidade acadêmica. Desde a CF de 1998, com raras exceções, esse primado foi reafirmado de forma ininterrupta. Todos os presidentes da República nomearam os primeiros colocados das listas tríplices. O governo Bolsonaro rompeu com essa tradição, tendo nomeado os reitores de acordo com os seus critérios e preferências, independente da posição na lista tríplice elaborada pelas instituições.

Quadro 2 - Nomeações de reitores para as Instituições Federais de Educação Superior no período entre março de 2019 a fevereiro de 2021

\begin{tabular}{|c|c|c|}
\hline INSTITUIÇÃO & POSIÇÃO NA LISTA TRÍPLICE & $\begin{array}{c}\text { DATA DA } \\
\text { NOMEAÇÃO }\end{array}$ \\
\hline Universidade da Integração Internacional da Lusofonia Afro-Brasileira & pro tempore (não constava na lista) & $10 / 03 / 2019$ \\
\hline Universidade Federal da Grande Dourados & pro tempore (não constava na lista) & $11 / 06 / 2019$ \\
\hline Universidade Federal do Triângulo Mineiro & $2^{\circ}$ colocado & $17 / 06 / 2019$ \\
\hline Universidade Federal do Estado do Rio de Janeiro & Não constava na lista tríplice & $17 / 06 / 2019$ \\
\hline Universidade Federal do Recôncavo da Bahia & $3^{\circ}$ colocado & $01 / 08 / 2019$ \\
\hline Universidade Federal dos Vales do Jequitinhonha e Mucuri & $3^{\circ}$ colocado & $10 / 08 / 2019$ \\
\hline Centro Federal de Educação Tecnológica do Rio de Janeiro & pro tempore (não constava na lista) & $15 / 08 / 2019$ \\
\hline Universidade Federal do Ceará & $2^{\circ}$ colocado & $19 / 08 / 2019$ \\
\hline Universidade Federal da Fronteira Sul & $3^{\circ}$ colocado & $30 / 08 / 2019$ \\
\hline Universidade Federal do Espírito Santo & $2^{\circ}$ colocado & $23 / 03 / 2020$ \\
\hline Universidade Federal do Vale do São Francisco & pro tempore (não constava na lista) & $09 / 04 / 2020$ \\
\hline Instituto Federal do Rio Grande do Norte & Não constava na lista & $17 / 04 / 2020$ \\
\hline Instituto Federal de Santa Catarina & $2^{\circ}$ colocado & $04 / 05 / 2020$ \\
\hline Universidade Federal do Semiárido & $3^{0}$ colocado & $21 / 05 / 2020$ \\
\hline Universidade Federal do Rio Grande do Sul & $3^{\circ}$ colocado & $15 / 09 / 2020$ \\
\hline Universidade Federal do Sul e Sudeste do Pará & $3^{\circ}$ colocado & $15 / 09 / 2020$ \\
\hline Universidade Federal da Paraíba & $3^{\circ}$ colocado & $04 / 11 / 2020$ \\
\hline Universidade Federal do Piauí & $2^{\circ}$ colocado & $18 / 11 / 2020$ \\
\hline Universidade Federal Sergipe & pro tempore (não constava na lista) & $20 / 11 / 2020$ \\
\hline Universidade Federal de Itajubá & $2^{\circ}$ colocado & $09 / 12 / 2020$ \\
\hline Universidade Federal de Pelotas & $2^{\circ}$ colocado & $06 / 01 / 2021$ \\
\hline Universidade Federal de São Carlos & $2^{\circ}$ colocado & $15 / 01 / 2021$ \\
\hline
\end{tabular}

OBS: O levantamento acima foi finalizado em fevereiro de 2021.

FONTE: Tabela elaborada pelos autores a partir dos dados disponíveis no Diário Oficial da União e nos sítios oficiais dos principais órgãos da imprensa.

O princípio da autonomia também vem sofrendo investidas no plano legal. A partir de junho de 2019, conforme quadro abaixo, o governo federal empreendeu várias tentativas com o propósito de alterar o regramento referente à eleição e nomeação de reitores, vice-reitores e diretores de unidades. 


\section{Quadro 3 - Propostas de alteração dos marcos regulatórios referentes ao princípio da autonomia universitária}

\begin{tabular}{|c|c|}
\hline MARCOS REGULATÓRIOS & CONTEÚDO \\
\hline $\begin{array}{l}\text { Decreto n }{ }^{0} 9.794 \text {, de junho } \\
\text { de } 2019\end{array}$ & $\begin{array}{l}\text { O Decreto estabelece que os reitores não poderão nomear pró-reitores e diretores de unidades. A } \\
\text { nomeação será competência dos ministros da Casa Civil e da Educação. Os servidores indicados } \\
\text { terão de passar por investigação de vida pregressa feita pela Agência Brasileira de Inteligência } \\
\text { (Abin) e pela Controladoria Geral da União (CGU). O Decreto fere os artigos 5, } 37 \text { e } 207 \text { da CF, } \\
\text { assim como, as Leis } 5.540 / 68 \text { e 8.112/90. }\end{array}$ \\
\hline $\begin{array}{l}\text { Medida Provisória n 914, de } \\
24 \text { de dezembro de } 2019\end{array}$ & $\begin{array}{l}\text { A MP foi editada um dia após o início do recesso parlamentar de 2019. Ela estabeleceu normas } \\
\text { para a escolha de reitores de universidades, institutos federais e do Colégio Pedro II, assim como } \\
\text { alterou a forma de nomeação de reitores e diretores de campi. A MP } 914 \text { não foi aprovada pelo } \\
\text { Congresso Nacional, tendo perdido sua validade em } 02 \text { de junho de } 2020 \text {. }\end{array}$ \\
\hline \multicolumn{2}{|l|}{ Projeto de Lei } \\
\hline \multicolumn{2}{|l|}{$n^{0} 3076$, de } \\
\hline 02 de junho de 2020 & $\begin{array}{l}\text { Trata-se do Projeto Future-se, que propõe alterações significativas na autonomia financeira e } \\
\text { patrimonial das universidades. }\end{array}$ \\
\hline $\begin{array}{l}\text { Medida Provisória n 979, de } \\
09 \text { de junho de } 2020\end{array}$ & $\begin{array}{l}\text { Poucos dias após a MP 914/19 ter perdido validade, o governo editou nova MP, desta vez } \\
\text { regulamentando a designação de dirigentes pro tempore para as IES federais cujos mandatos se } \\
\text { encerram até } 31 \text { de dezembro de 2020, correspondente ao período de emergência da COVID-19 } \\
\text { (Lei n } \text { n }^{\circ} 13.979 \text {, de } 6 \text { de fevereiro de 2020). De acordo com a MP 979, as IFES ficam desobrigadas } \\
\text { a realizar consulta pública à comunidade acadêmica e a formar a lista tríplice para ser enviada } \\
\text { ao MEC. }\end{array}$ \\
\hline $\begin{array}{l}\text { Portaria } n^{0} 545 \text {, de } 16 \text { de } \\
\text { junho de } 2020\end{array}$ & $\begin{array}{l}\text { Extinguiu a reserva de vagas para pessoas com deficiência, negros e indígenas em programas } \\
\text { de pós-graduação nas IFES. Revogou também a Portaria Normativa n } 13 \text {, de } 11 \text { de maio de } 16 . \\
\text { A Portaria } 545 \text { foi publicada pelo então Ministro da Educação Abraham Weintraub, dois dias antes } \\
\text { de sua exoneração do cargo. }\end{array}$ \\
\hline $\begin{array}{l}\text { Portaria } n^{0} 559 \text {, de } 22 \text { de } \\
\text { junho de } 2020\end{array}$ & $\begin{array}{l}\text { Em virtude das críticas recebidas, o MEC decidiu publicar nova portaria (seis dias depois), } \\
\text { tornando sem efeito a Portaria } 545 .\end{array}$ \\
\hline
\end{tabular}

FONTE: Tabela elaborada pelos autores a partir dos dados disponíveis no Diário Oficial da União.

A Medida Provisória no 979, de 09 de junho de 2020, evidencia, entre outros aspectos, a inconstitucionalidade das tentativas de alteração dos marcos regulatórios que regem a autonomia universitária. O flagrante desvio da lei motivou o presidente do Senado Federal, Davi Alcolumbre, a devolver referida MP ao poder executivo. Em despacho datado de 12 de junho de 2020, o então presidente do Senado (ALCOLUMBRE, 2020) assim se referiu:

Acabo de assinar o expediente de devolução da MP 979, que trata da designação de reitores, por violação aos princípios constitucionais da autonomia e da gestão democrática das universidades. Cabe a mim, como presidente do Congresso Nacional, não deixar tramitar proposições que violem a Constituição Federal. O Parlamento permanece vigilante na defesa das instituições e no avanço da ciência. 
A devolução sem análise é uma prática excepcional. Trata-se de um expediente extremo, utilizado pelo Congresso Nacional apenas quatro vezes entre 1985 e 2020, ocorridos nos governos José Sarney (MP 33/1989), Luiz Inácio Lula da Silva (MP 446/2008), Dilma Rousseff (MP 669/2015) e Jair Bolsonaro (MP 979/20). A devolução, sem análise, torna a MP sem efeito.

Mais recentemente, o governo federal, por meio do Ministério da Educação, elaborou e enviou ao Congresso um projeto de lei que pretende rever dimensões centrais da autonomia universitária, especialmente no que tange aos aspectos administrativos, financeiros e patrimoniais. Trata-se do Projeto de Lei $\mathrm{n}^{\mathrm{o}}$ 3.076/20. O projeto Future-se, como assim é denominado, propõe uma drástica redução da função pública das universidades, induz a privatização do patrimônio tangível e intangível das instituições e introduz mecanismos que agilizam as parcerias entre as instituições públicas e os agentes privados. O Projeto de Lei encontra-se, atualmente, na coordenação de comissões permanentes da Câmara dos Deputados, aguardando tramitação.

\section{CONSIDERAÇÕES FINAIS}

A pesquisa evidenciou uma estreita correlação entre democracia e autonomia. A trajetória de uma se confunde com a outra. Como a democracia no Brasil tem sido mais a exceção que a regra, as universidades brasileiras passaram a maior parte de sua história sob a tutela e o controle direto ou indireto dos governos autoritários. Os regimes autoritários, invariavelmente, moveram ações para suprimir as liberdades acadêmicas e de cátedra, assim como restringiram o direito das instituições de definirem as suas regras relativas à gestão administrativa e financeira.

A trajetória do princípio da autonomia no Brasil não é linear. Trata-se de um processo com oscilações, característico a um pêndulo, ora promovendo avanços, ora retrocessos. Como observado ao longo deste artigo, a primeira Carta Magna brasileira - entre as sete no período entre 1824 e 1988 - a constitucionalizar o princípio da autonomia universitária foi a de 1988. Ele foi firmado no bojo do processo de democratização do país e da institucionalização dos direitos civis, políticos e sociais fundamentais.

Transcorridos mais de trinta anos da CF de 1988, a autonomia segue polêmica e ensejando disputas. O Supremo Tribunal Federal (STF) é, com frequência, demandado a fixar entendimentos sobre a matéria. A mais recente ação (ADPF 759) foi ajuizada pelo Conselho Federal da OAB em 11 de novembro de 2020. A ADPF questiona a constitucionalidade das "nomeações discricionárias" do presidente da República. De acordo com a ação, as nomeações que não observam 
a ordem hierárquica da lista tríplice caracterizam "desrespeito aos princípios constitucionais da gestão democrática, do republicanismo, do pluralismo político e da autonomia universitária" (ADPF 759). Em 08 de fevereiro de 2021, o pleno do STF decidiu, por maioria (8x3), acompanhar o voto do Ministro Alexandre de Moraes. De acordo com o parecer do Ministro, “[...] A escolha de seu dirigente máximo pelo Chefe do Poder Executivo, a partir de lista tríplice, com atribuições eminentemente executivas, não prejudica ou perturba o exercício da autonomia universitária, não significando ato de fiscalização ou interferência na escolha ou execução de políticas próprias da instituição, escolhidas por decisão colegiada e participativa de seus integrantes" (MORAES, 2021, p. 01). De acordo com a decisão do STF, o presidente da República não precisa observar a ordem da lista tríplice para nomear reitores e vice-reitores das universidades federais.

\section{REFERENNCIAS}

ALCOLUMBRE, Davi. Davi Alcolumbre anuncia devolução de MP que autoriza Weintraub a nomear reitores. Disponível em: https://www12.senado. leg.br/noticias/materias/2020/06/12/davi-alcolumbre-anuncia-devolucao-demp-que-autoriza-weintraub-a-nomear-reitores. Acesso em: 17 de junho de 2020.

BARRETO, Arnaldo Lyrio. Origens da universidade brasileira. Disponível em: http://www.scielo.br/pdf/qn/v30n7/49.pdf. Acesso em 26 de janeiro de 2020.

BRASIL. Constituição da República Federativa do Brasil. Brasília: Congresso Nacional, 1988. Disponível em: http://www.planalto.gov.br/ccivil_03/ constituicao/constituicaocompilado.htm. Acesso em: 27 de janeiro de 2020.

Decreto $\mathrm{n}^{\mathrm{o}} \mathbf{1 9 . 5 4 7}$ de 30 de dezembro de 1930. Disponível em: https:/ / www2.camara.leg.br/legin/fed/decret/1930-1939/decreto-19547-30dezembro-1930-513446-publicacaooriginal-1-pe.html. Acesso em: 27 de janeiro de 2020 .

. Decreto $\mathbf{n}^{\mathbf{0}} \mathbf{1 9 . 8 5 0}$, de 11 de abril de 1931. Disponível em: https:// www2.camara.leg.br/legin/fed/decret/1930-1939/decreto-19850-11-abril-1931515692-exposicaodemotivos-141249-pe.html. Acesso em: 14 de maio de 2020. 
Decreto $\mathrm{n}^{\circ}$ 19.851, de 11 de abril de 1931. Disponível em: https:// www2.camara.leg.br/legin/fed/decret/1930-1939/decreto-19851-11-abril-1931505837-publicacaooriginal-1-pe.html. Acesso em: 13 de maio de 2020.

Lei n ${ }^{\circ}$.024 de 20 de dezembro de 1961. Brasília, 1961. Disponível em: https://www2.camara.leg.br/legin/fed/lei/1960-1969/lei-4024-20-dezembro1961-353722-publicacaooriginal-1-pl.html. Acesso em: 27 de maio de 2020.

Lei n ${ }^{\circ} \mathbf{5 . 5 4 0}$ de 28 de novembro de 1968. Brasília, 1968. Disponível em: https://www2.camara.leg.br/legin/ fed/lei/1960-1969/lei-5540-28-novembro1968-359201-publicacaooriginal-1-pl.html. Acesso em: 27 de janeiro de 2020.

CARRANO, Paulo. Toda ditadura quer controlar o campo educacional, porque é nele que há liberdade para pensar e construir novos caminhos para a sociedade. Disponível em: http://www.epsjv.fiocruz.br/noticias/ entrevista/toda-ditadura-quer-controlar-o-campo-educacional-porque-e-neleque-ha-liberdade. Acesso em 10 de janeiro de 2020.

CIRNE, Maria Barbosa. Francisco Campos e a reforma universitária de 1931: um resgate sobre os seus ecos no princípio da autonomia universitária. 2018. Disponível em: https://www.indexlaw.org/index.php/historiadireito/ article/view/4030/pdf. Acesso em 22 de janeiro de 2020.

CHAUI, Marilena. A universidade pública sob nova perspectiva. 2003. Disponível em: http://www.scielo.br/pdf/rbedu/n24/n24a02.pdf. Acesso em 22 de abril de 2020.

DURHAM, Eunice Ribeiro. A autonomia universitária: o princípio constitucional e as suas implicações. 1989. Disponível em: http://nupps.usp. br/downloads/docs/dt8909.pdf. Acesso em: jun. 2020.

FÁVERO, Maria de Lourdes de Albuquerque. A Universidade no Brasil: das origens à Reforma Universitária de 1968. 2006. Disponível em: http://www. scielo.br/pdf/er/n28/a03n28.pdf. Acesso em 20 de janeiro de 2020.

FREITAG, Bárbara. Escola, estado e sociedade. São Paulo: Moraes, 1980. 
GERMANO, José Willington. Estado militar e educação no Brasil (19641985). 3 ed. São Paulo: Cortez, 2000.

LEHER, Roberto. Autonomia universitária e liberdade acadêmica. 2019. Disponível em: https://revistas.ufrj.br/index.php/rce/article/view/23167. Acesso em 20 de janeiro de 2020.

MARTINS, Antonio Carlos Pereira. Ensino superior no Brasil: da descoberta aos dias atuais. 2002. Disponível em: http://www.scielo.br/pdf/acb/ v17s3/15255.pdf. Acesso em 26 de janeiro de 2020.

MARTINS, Carlos Benedito; AZEVEDO, Sérgio de. Autonomia Universitária: Notas sobre a Reestruturação do Sistema Federal de Ensino Superior. Disponível em: https://anpocs.com/index.php/bib-pt/bib-46/491-autonomiauniversitaria-notas-sobre-a-reestruturacao-do-sistema-federal-de-ensinosuperior/file. Acesso em 22 de abril de 2020.

MEYER, Emílio. Autonomia universitária, democracia e federalismo. 2019. Disponível em: http://www.culturasjuridicas.uff.br/index.php/rcj/article/ view/758. Acesso em 11 de janeiro de 2020.

MORAES, Ricardo. No Roda Viva, Bolsonaro questiona escravidão e cotas. Disponível em: https://exame.abril.com.br/brasil/no-roda-viva-bolsonaroquestiona-escravidao-e-cotas. Acesso em 21 de janeiro de 2020.

MORAES, Alexandre de. Parecer sobre a ADPF 759. Supremo Tribunal Federal. Disponível em: http://portal.stf.jus.br/processos/detalhe. asp?incidente $=6045159$. Acesso em: 09 fev. 2021.

POZZEBOM, Fabio Rodrigues. Ministro da Educação diz que universidades federais plantam maconha. 2019. Disponível em: https:/ /exame.abril.com.br/ brasil/ministro-da-educacao-diz-que-universidades-federais-plantam-maconha/. Acesso em 26 de janeiro de 2020.

RANIERI, Nina Beatriz Stocco; LUTAIF, Michel Kurdoglian. A autonomia universitária e seus percalços. Disponível em: http://www.comciencia.br/ autonomia-universitaria-e-seus-percalcos/. Acesso em 29 de janeiro de 2020. 
RANIERI, Nina Beatriz Stocco. Trinta anos de autonomia universitária: resultados diversos, efeitos contraditórios. Disponível em: http://www.scielo. br/pdf/es/v39n145/1678-4626-es-es0101-73302018205173.pdf. Acesso em 10 de janeiro de 2020.

ROSSATO, Ricardo. Universidade: nove séculos de história. Passo Fundo: UPF, 1998.

ROMANELLI, Otaíza. História da educação no Brasil. Petrópolis, Vozes, 1978.

STF. Supremo Tribunal Federal. Arguição de Descumprimento de Preceito Fundamental (ADPF) 548. Liminar proferida pela Ministra Cármem Lúcia. Disponível em: http://www.stf.jus.br/arquivo/cms/noticiaNoticiaStf/ anexo/adpf548liminar.pdf. Acesso em: abril de 2020.

TEIXEIRA, Anísio. Ensino superior no Brasil: análise e interpretação de sua evolução até 1969. Rio de Janeiro: Editora da Fundação Getúlio Vargas, 1989.

\section{Joviles Vitório Trevisol}

Doutor em Sociologia pela Universidade de São Paulo. Pós-doutor em Sociologia pelo Centro de Estudos Sociais da Universidade de Coimbra. Docente pesquisador do Programa de Pós-Graduação em Educação da UFFS. E-mail: joviles.trevisol@uffs.edu.br

\section{Ricardo Garmus}

Licenciado em Ciências Sociais pela Universidade Federal da Fronteira Sul. Servidor Público Federal. Mestrando em Educação pelo Programa de PósGraduação em Educação da UFFS. E-mail: ricardo.garmus@uffs.edu.br 